\title{
art@CMS SciArt Workshops
}

\author{
Michael Hoch ${ }^{1,2}$ \\ Austrian Academy of Sciences, Austria \\ E-mail: michael.hochecern.ch
}

\section{Angelos Alexopoulos ${ }^{2}$}

CERN, Switzerland

E-mail: angelos.alexopoulosecern.ch

\section{Stephen Preece}

International School of Geneva, Switzerland

E-mail: stephen.preece@gmail.com

\section{Mick Storr}

University of Birmingham, UK / CERN, Switzerland

E-mail: mick.storracern.ch

\section{Achille Petrilli ${ }^{2}$}

CERN, Switzerland

E-mail: achille.petrilli@cern.ch

Recent developments in science education policy and practice suggest that successful learning in the 21 st century requires the horizontal connectedness across areas of knowledge by linking the arts and humanities with science, technology, engineering and mathematics (STEM) subjects. The rapidly increasing STEAM movement calls for arts integration into science teaching and learning to help school students develop skills that are necessary to thrive in an innovation economy. Education and outreach in high-energy physics are not an exception to these developments. This paper outlines a series of learning activities for students at secondary and tertiary level that use a cross-disciplinary approach to fostering creativity and imagination in physics education and outreach.

$38^{\text {th }}$ International Conference on High Energy Physics

3-10 August 2016

Chicago, USA

\footnotetext{
${ }^{1}$ Speaker.

2 On behalf of the CMS collaboration.
} 


\section{Introduction}

Recent years have seen a growing consensus in the science education community that STEM teaching and learning at school and tertiary level can benefit considerably from the introduction of the arts [1]. The so-called STEAM movement has also been recognized by science education policy makers as a useful framework for helping young people establish and advance $21^{\text {st }}$ century skills and competencies that are necessary to thrive in an innovation economy [2]. Arts integration into science learning goes, however, beyond calls for employability skills development alone, by emphasizing that "science is an activity that involves creativity and imagination as much as many other human activities" [3].

If we accept that "creativity is as important in education as literacy and should be treated with the same status" [4], it is then reasonable to think that a shift from STEM to STEAM may also be of value in physics education research and practice. In this paper, we present an overview of art@CMS SciArt workshops, a STEAM initiative undertaken recently by the Communications group of the CMS collaboration. art@CMS SciArt workshops rest on the idea that successful learning in the $21^{\text {st }}$ century depends on "horizontal connectedness across areas of knowledge and subjects as well as to the community and the wider world" [5]. We argue that large research infrastructures, including those in high-energy physics, have strong potential in this regard because of their capacity to act as incubators for innovative ideas and projects that can generate positive externalities for society by infusing creativity into their education and outreach activities [6].

\section{STEAM activities in CMS}

STEAM in CMS is situated principally within art@CMS [8][9], an education and outreach programme that was founded in 2012 by Austrian particle physicist, photographer and artist Michael Hoch. As evidenced in his recently published photographic work [10], Hoch introduced the idea that the inherent beauty and symmetry of the CMS detector can evoke wonder, curiosity and interest in particle physics by the public and especially by young people. With the support of the CMS Collaboration, and more recently of the CREATIONS EU project [11], art@CMS has evolved into a solid education and outreach programme with two complementary modules: exhibitions for the general public, and SciArt workshops for secondary school and third-level students. As of mid-2016 almost 145,000 people have visited 42 art@CMS exhibitions organized in 25 cities across 17 countries in four continents. These are often combined with LHC-related events such as public talks, conferences and science festivals with the participation of the local communities, serving as forums for dialogue on the role of science in society. For the purposes of this paper, we will focus on the SciArt workshops only.

\subsubsection{SciArt workshops}

SciArt workshops are cross-disciplinary learning activities designed to introduce school, college and university students to the scientific world of particle physics and fundamental research through artistic inquiry and creation. They incorporate an introduction to particle physics, CMS and CERN, followed by philosophical reflection and discussion aimed at inspiring the students 
art@CMS SciArt Workshops

to develop their own science-related art works. The students then have the opportunity to mount an exhibition of their work.

SciArt workshops aim to foster skills that are more appropriate to the challenges of the 21 st century. Much work has already been done to quantify the benefits of developing skills such as creativity, critical thinking and collaboration [12]. Acting like an ideas factory, SciArt workshops are built on a platform for learning, sharing and sustainable personal development. They are ultimately a form of learner(s) hub where the individual can take ownership of their ideas, and turn those ideas into tangible products of imaginative thinking that embody both aesthetic and educational value [13]. Since 2013, 13 SciArt workshops have taken place in seven countries engaging 700 school, college and university students. Two examples of such workshops are presented briefly below.

\subsubsection{High energy physics meets art (Graz, Austria, June 2013)}

The first in the series of art@CMS SciArt workshops took place in Graz, Austria, with the participation of 62 high-school students from two local schools: GIBS and BORG. This threeday workshop was supported by CMS, the Institute for High Energy Physics of the Austrian Academy of Science (HEPHY) with the collaboration of the National History Museum in Graz and the City of Graz.

On the first day, HEPHY physicists delivered a Masterclass where the students learned to visualise and analyse real LHC data from the CMS experiment. The students were then introduced to the interconnections of science and the arts by learning how artists visualise science and technology in their works. On the second day, four groups of students under the guidance of art educators and scientists, created their own art works inspired by particle physics. A separate group of students documented the whole workshop with photos, a video and a dedicated blog. On the last day, the art works were displayed for public viewing at Graz's National History Museum attracting 200 visitors, including parents and other students.

\subsubsection{Imagining physics: art inspired by Fermilab (Batavia, US, February 2015)}

Through a collaboration between Fermilab, Water Street Studios, local artists and high-school students, a SciArt workshop, entitled "Imaging Physics" was organized in Batavia, US, in February 2015 as part of an art@CMS exhibition hosted by Fermilab Art Gallery. The workshop brought together 18 high school art students with the aim to introduce them into the world particle physics and to challenge them to turn their impressions into art.

Over the course of two weeks, the students worked collaboratively under the guidance of their teachers and professional artists from Water Street Studios to create artworks inspired by particle physics. They first visited Fermilab where they took part in presentations by physicists and also learned about art@CMS from Michael Hoch. Four hands-on meetings were then organised in Water Street Studios during which the students worked on their ideas by developing art works that encapsulated how particle physics connect to their own lives. The art works were then transferred to Fermilab Art Gallery for public viewing."Having the Art@CMS pieces here at Fermilab is outstanding," said Georgia Schwender, curator of the Fermilab Art Gallery. "But having the chance to connect the art and science of the CMS experiment with students outside the laboratory makes this event a true example of our mission." [14] 


\section{art@CMS SciArt Workshops \\ Conclusion}

3.

This paper presented a set of novel education and outreach activities by the CMS collaboration that fall into the STEAM movement. We argue that art@CMS SciArt workshops can play a transformative role in enabling high-energy physics to become accessible to larger and more diverse student audiences while also encouraging the development of $21^{\text {st }}$ century skills to the next generation of learners regardless if they decide to follow scientific careers or not.

\section{Acknowledgements}

The art@CMS activities presented in this paper are partially funded by the European Union in the context of the CREATIONS project (Grant Agreement no. 665917) under the "Science with and for Society" section of the Horizon 2020 Work Programme. This document does not represent the opinion of the European Union, and the European Union is not responsible for any use that might be made of its content.

\section{References}

[1] Y. Hadzigeorgiou, Imaginative science education, Springer, 2016.

[2] C. Ryan et al., Science education for responsible citizenship, European Commission, 2015.

[3] J. Osborne et al., What "ideas-about-science" should be taught at school? A Delphi study of the expert community, Journal of Research in Science Teaching 40 (2003).

[4] K. Robinson, Do schools kill creativity? (video), 2006. Retrieved from http://www.ted.com/index.php/talks/view/id/66

[5] J. Graff, Practitioner guide. The nature of learning: Using research to inspire practice, OECD, 2012.

[6] U. Billow et al., Resources for $E \& O$, in proceedings of EPS-HEP conference, PoS(EPSHEP2015)619.

[7] http://cms.cern

[8] M. Hoch, A. Alexopoulos, Art@CMS and Science\&Art@School: Novel education and communication channels for particle physics, DOI: http://dx.doi.org/10.1142/9789814603164_0115

[9] http://cern.ch/artcms

[10] M. Hoch et al., CMS - The art of science, Edition Lammerhuber, 2016.

[11] http://creations-project.eu

[12] R. Paul, L. Elder, A guide for education to critical thinking competency standards: Standards, principles, performance, Foundation for Critical Thinking, 2005.

[13] http://cylindricalonion.web.cern.ch/blog/201509/science-and-art-combine-international-schoolgeneva

[14] http://news.fnal.gov/2015/01/arts-extravaganza-at-fermilab-to-celebrate-one-of-the-worlds-largestscience-experiments/ 